\title{
Patient with prostatic adenocarcinoma with plasmacytoid features and an aberrant immunohistochemical phenotype diagnosed by biopsy and a mini-review of plasmacytoid features in the genitourinary system: A case report
}

\author{
KONSTANTINA ZACHAROULI, DIMITRA P. VAGELI, GEORGE K. KOUKOULIS and MARIA IOANNOU
}

\author{
Department of Pathology, Faculty of Medicine, School of Health Sciences, \\ University of Thessaly, Biopolis, 41500 Larissa, Greece
}

Received November 15, 2021; Accepted December 31, 2021

DOI: $10.3892 / \mathrm{mco} .2022 .2500$

\begin{abstract}
Prostate cancer is one of the most commonly diagnosed malignancies in men. Most of these tumors are adenocarcinomas. Plasmacytoid is a rare variant of adenocarcinoma described by previous studies in the genitourinary system and is characterized by the plasmacytoid appearance of tumor cells with abundant cytoplasm and abnormally placed hyperchromatic nuclei. However, to the best of our knowledge, plasmacytoid adenocarcinoma has rarely been described in the prostate. This report describes a new case of plasmacytoid adenocarcinoma of the prostate diagnosed by biopsy and summarizes the known literature on plasmacytoid features in the genitourinary system. A 62-year-old male patient presented to the hospital with urinary retention, hematuria, weakness and weight loss. The digital rectal examination revealed an irregular enlargement. Laboratory findings showed elevated levels of prostate specific antigen (PSA; $43.6 \mathrm{ng} / \mathrm{ml}$ ). Transrectal ultrasound showed invasion of the right seminal vesicle. Prostate tumor core biopsies were collected and sent for diagnosis. Histological examination revealed a high-grade prostatic adenocarcinoma Gleason score of 5+5 (total score 10). The tumor cells had a plasmacytoid appearance with abundant cytoplasm and abnormally placed hyperchromatic nuclei. The immunohistochemical phenotype was characterized by abundant positivity for cytokeratin (CK) AE1/AE3 and PSA. By contrast, tumor cells were negative for p63, CK 34BE12 and GATA binding protein 3 (urothelial markers), synaptophysin (neuroendocrine marker). Tumor cells were also negative for E-cadherin, which is particularly indica-
\end{abstract}

Correspondence to: Dr Dimitra P. Vageli, Department of Pathology, Faculty of Medicine, School of Health Sciences, University of Thessaly, Panepistimiou 3, Biopolis, 41500 Larissa, Greece

E-mail: dimitra.vangeli@gmail.com

Key words: plasmacytoid, prostate cancer, urothelial cancer, genitourinary system, E-cadherin, prostate specific antigen, biopsy tive of $C D H 1$ alterations. To the best of our knowledge, this is the first description of a plasmacytoid adenocarcinoma of the prostate diagnosed by biopsy, showing an irregular immunophenotype that may indicate somatic $\mathrm{CDH} 1$ alterations. The presentation of a novel rare variant of prostatic carcinoma that differs from other neoplasms of the genitourinary system may contribute to an improved understanding of this uncommonly found histological pattern that may also be mandatory due to the clinical and prognostic implications of this diagnosis.

\section{Introduction}

According to Global Cancer Statistics (GLOBOCAN) 2020, prostate cancer is the third most commonly diagnosed malignancy $(7.3 \%)$, preceded only by lung $(11.4 \%)$ and colorectal cancer $(10.0 \%)$ (1). Prostate cancer is the most commonly diagnosed cancer in men in over $50 \%$ of countries in the world. Prostate cancer incidence varies substantially between countries with a high Human Development Index (HDI), such as Europe and North America, and those with a low HDI, such as Asia (37.5 vs. 11.3 per 100,000 people, respectively). However, cases are increasing in Asian countries such as Japan and Singapore where, historically, this cancer had a low incidence rate and prostate-specific antigen (PSA) testing was minimal (2). The introduction of PSA testing worldwide allowed the detection of preclinical prostate cancers, decreasing the mortality rates for prostate cancer in most high-income countries. The etiology of prostate cancer is not clear yet, and except the advanced age, family history of this malignancy, and genetic predisposition (e.g., BRAC1 and BRAC2, Lynch syndrome), other factors including smoking, excess body weight, and nutritional factors may increase the risk of prostate cancer. In addition, although the Gleason score is currently the best prognostic indicator for this cancer, grading of prostate cancer based on its molecular profile is considered an independent factor to predict poor outcomes in patients with low Gleason scores (3). The above makes clear the need for a better understanding of the pathophysiology of prostate cancer and whether variable histologic features present different molecular phenotypes.

The vast majority of prostatic cancers are acinar adenocarcinomas, including eight histological variants, according 
to 2016 the World Health Organization (WHO) classification. The atrophic, pseudo-hyperplastic, microcystic, and foamy variants have a false benign appearance and can be misdiagnosed. The signet ring-like cell, pleomorphic giant cell, and sarcomatoid variants harbor prognostic significance, with a worse prognosis compared to the usual acinar adenocarcinoma (3-5). Plasmacytoid is a rare variant of acinar prostatic adenocarcinoma and has been reported little. Plasmacytoid carcinoma appeared with a single ring-like cell pattern and has been characterized by the presence of discohesive cells with eccentrically placed nuclei and abundant eosinophilic cytoplasm (5-7). In the literature, there are two previous descriptions of prostate carcinoma with plasmacytoid features $(8,9)$. In these cases, the patients had lymphovascular invasion and advanced-stage disease (Gleason score $>8$ ). In the first case, Al-Hussain et al (8) used histological and immunohistochemical analyses and identified a plasmacytoid variant of prostatic adenocarcinoma with signet ring-like cell appearance, undermining benign urothelium. This tumor was initially considered histologically as a plasmacytoid variant of urothelial carcinoma, given the lack of a morphological counterpart in the prostate and the distinct features of a loss of E-cadherin. However, PSA and NKX3 immunoreactivity confirmed a prostatic adenocarcinoma with plasmacytoid features. Subsequently, Nguyen et al (9) reviewed a series of radical prostatectomies with high-grade prostatic adenocarcinoma and found a tumor with a component of single-cell infiltration, and significant morphological overlap with the plasmacytoid variant of urothelial carcinoma, diffuse-type gastric adenocarcinoma, and lobular breast carcinoma. Immunohistochemical analysis for NKX3.1 and PSA confirmed a prostatic adenocarcinoma with plasmacytoid features.

Plasmacytoid carcinomas have been described in the urothelium (5-7,10-14), the ureter (15), and the renal pelvis (16), while plasmacytoid morphology is not limited to urothelial carcinoma and plasmacytoid prostate carcinoma, which presents PSA and NKX 3.1 immunoreactivity, must be distinguished from other plasmacytoid neoplasms. However, the plasmacytoid variant of both urothelial and prostate carcinomas shares some common molecular features. In particular, the distinctive feature of E-Cadherin loss suggests that it may play a role in the development of the plasmacytoid pattern of both bladder and prostate carcinoma (17-19) while it may be accompanied by aberrant expression of p120 catenin (20). The loss of E-cadherin and the abnormal protein expression of p120 catenin, found by immunohistochemical analysis, strongly suggest changes in $\mathrm{CDH}$ l encoding E-Cadherin. However, studies have shown that other molecular pathways may also play a role in this histopathological phenotype $(8,21)$. Specifically, Al-Hussain et al (8) identified several putative driver alterations in FANCA, MET, SMARCA4, in addition to frameshift deletions in $B R A F$ and $K D R$, and loss of copy number at the $R B 1$ locus. However, they found no genomic alterations in the $\mathrm{CDH} 1$ gene.

Plasmacytoid carcinomas of the genitourinary tract are associated with locally advanced disease and a tendency for lymph node involvement at onset $(5,9,10,12,13)$. Plasmacytoid prostate tumors can be locally invasive and misdiagnosed as urothelial carcinomas. This may emphasize the importance of identifying and reporting more cases and better understanding their pathophysiological features. Here we report a case of a plasmacytoid variant of acinar adenocarcinoma of the prostate with an irregular immunohistochemical phenotype on biopsy and summarize the known literature on plasmacytoid feature in the genitourinary system. We also discuss the importance of distinguishing this variant, which is characterized by a unique histological feature and molecular phenotype, from other prostate carcinomas and neoplasms of the urinary tract that may be mandatory due to the clinical and prognostic implications of this diagnosis.

\section{Case report}

A 62-year-old male proceeded to the outpatient urology department with urinary retention, hematuria, weakness, and weight loss. The digital rectal examination was deemed malignant enlargement. Laboratory findings showed elevated levels of prostate specific antigen (PSA: $43.6 \mathrm{ng} / \mathrm{ml}$ ). Ultrasound showed invasion of the right seminal vesicle. The patient underwent transrectal ultrasound to guide prostate biopsy. Prostate biopsy cores were sent to the Department of Pathology (University of Thessaly, Greece) for diagnosis.

Samples were fixed in $10 \%$ neutral buffered formalin ( $\mathrm{pH}$ 7.4) for $24 \mathrm{~h}$, at room temperature, dehydrated in a graded series of ethanol and xylene, and embedded into paraffin wax. Three $\mu \mathrm{m}$ sections were used for histological staining (hematoxylin and eosin, H\&E; hematoxylin incubation for $3 \mathrm{~min}$ at room temperature; eosin incubation for $5 \mathrm{~min}$ at room temperature). Serial $4 \mu \mathrm{m}$ sections were used for immunohistochemical (IHC) chromogenic staining. We used antibodies against Cytokeratin cocktail (clone AE1/AE3, 1:200, 313M-16, Cell Marque Corp.), high molecular weight Cytokeratin, (clone 34BE12, 1:100, Z2019ML, Zeta Corp.), PSA (clone ER-PR8, 1:50, M0750, Dako; Agilent Technologies, Inc.), p63 (clone 4A4, 1:100, M7317, Dako; Agilent Technologies, Inc.), GATA-3 (clone L50-823, 1:100, Z2227ML, Zeta Corp.), synaptophysin (clone 27G12, 1:100, SYNAP-299-L-CE, Leica Biosystems, Newcastle Ltd.) and E-cadherin (clone NCH-38, 1:100, M3612, Dako; Agilent Technologies, Inc.). All primary antibodies were incubated at room temperature, for $30 \mathrm{~min}$. Prior to the antibody incubation, $3 \%$ hydrogen peroxide was used for blocking endogenous peroxidase (15 $\mathrm{min}$ at room temperature). Positive staining was visualized with Bright Vision Ultimate plus kit [twocomponent detection system Goat Anti-Mouse/Rabbit IgG HRP (horseradish peroxidase), ready to use, $30 \mathrm{~min}$ incubation at room temperature; Immunologic, Holland], using DAB as chromogen. Microscopic examination and image analysis after histological and IHC staining was performed using laboratory rectifier microscope Nikon 50i (Nikon Solutions Co. Ltd.), with trioptic head and digital camera Basler (Basler AG), and mvSlide software (Microvisioneer).

Microscopic examination of biopsy sections was performed after histological staining (hematoxylin and eosin, $\mathrm{H} \& \mathrm{E}$ ) and revealed diffuse, neoplastic infiltration of prostate biopsy cores. The malignant single-cell pattern was presented with a plasmacytoid appearance with abundant cytoplasm and eccentrically placed hyperchromatic nuclei with small occasional nucleoli and variable intracytoplasmic features 
(Fig. 1), as previously described by Al-Hussain et al (8) and Nguyen et al (9), while there were a few mitotic figures. Immunohistochemical staining revealed abundant positivity for cytokeratins CKAE1/AE3 (Fig. 2A) and PSA (Fig. 2B), while tumor cells were negative for p63, cytokeratin 34BE12, GATA3, synaptophysin, and E-Cadherin (Fig. 2C). Specifically, compared to the normal prostatic acini that showed positive membranous immunoreactivity (Fig. 2C-a), the tumor cells were found to be negative for E-cadherin (Fig. 2C-b). Genomic analysis for $C D H 1$ alterations was not performed for the present case (Table I). The diagnosis was high-grade prostatic adenocarcinoma Gleason score of $5+5$ (total score 10) with plasmacytoid features. Computed tomography $(\mathrm{CT})$ scan did not reveal any metastases at the time of diagnosis. Our histological and laboratory findings, including clinical stage T3bNxM0, Gleason score $10(5+5)$ and PSA (before treatment) $43.6 \mathrm{ng} / \mathrm{ml}$, supported a high-risk prostate carcinoma, according to National Comprehensive Cancer Network (NCCN) guidelines, which defined the baseline of localized high-risk prostate cancer as PSA $>20 \mathrm{ng} / \mathrm{ml}$, clinical stage $\geq \mathrm{T} 3 \mathrm{a}$ and Gleason score $\geq 8$ (22) (Table II). This case was diagnosed by biopsy. However, no tissue specimens or patient's follow-up were provided after radical prostatectomy to our hospital. The patient is now alive, six months after diagnosis.

\section{Discussion}

Prostatic acinar adenocarcinoma represents a clinically and histologically heterogeneous disease. Several variants of prostatic adenocarcinoma have been recognized. The pathologist should recognize these variants because some of them present diagnostic challenges while others have prognostic implications. Variants of prostatic carcinomas, such as atrophic, pseudo-hyperplastic, microcystic, and foamy gland, can mimic benign conditions and therefore pose diagnostic challenges (23-28), while pleomorphic giant cell adenocarcinoma and sarcomatoid carcinoma are aggressive variants of prostate cancer (29-31). Pleomorphic giant cell adenocarcinoma is an extremely aggressive variant with extensive metastases, with death reported soon after diagnosis $(29,30)$. Also, Hansel and Epstein (31) reported 42 cases of sarcomatoid carcinoma of the prostate, in which half of the patients developed metastasis, while one-year mortality was found in $20 \%$ of the patients. Because of the diverse morphological patterns of prostate cancer, grading systems based on architectural methods, such as the Gleason score, are used to determine prostate cancer aggression (32-35). Two grades are assigned for each patient and typical total Gleason scores range from 6-10. A total Gleason score of 8 or higher describes high-grade prostate cancers that are likely to spread rapidly. Signet ring-like cell variant of prostate cancer is usually an aggressive tumor with an architectural model that most of the tumor is grade 4 and the next largest section of the tumor is grade 5 (Gleason score $4+5=9$ ), while rarely we can see signet ring-like cell vacuoles in well-formed glands of the pattern 3. The histologic pattern, which defines a high Gleason score, is characterized by single infiltrating cells (34), and has significant morphological overlap with other carcinoma variants developing into a diffuse, discohesive pattern with minimal stromal reaction, such as the plasmacytoid variant of

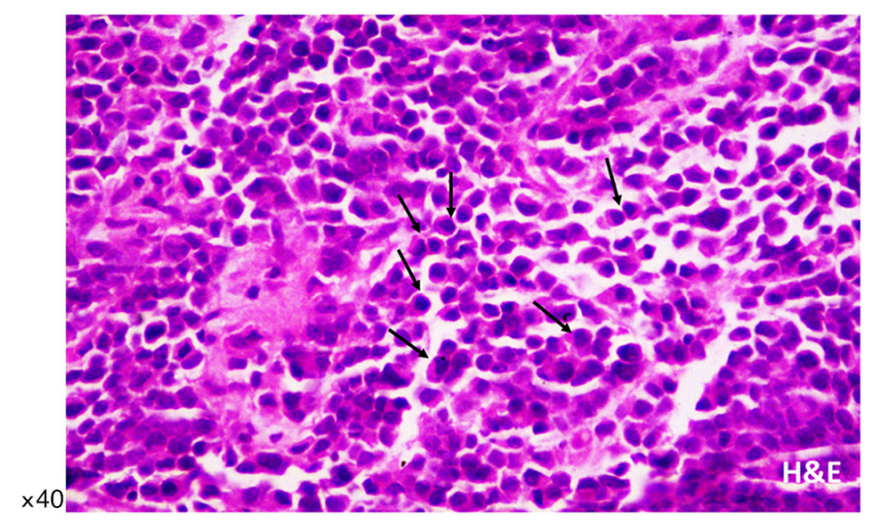

Figure 1. Plasmacytoid adenocarcinoma of the prostate. Histology shows diffuse infiltration of tumor cells with plasmacytoid features (arrows). Hematoxylin and eosin staining (original magnification, $\mathrm{x} 40$ ).

urothelial carcinoma (36), diffuse-type gastric cancer $(37,38)$, and lobular breast cancer (39), and is highly associated with $C D H 1$ alterations. This histological pattern is a rare variant of prostatic adenocarcinoma that has been classified as plasmacytoid carcinoma.

The first reported case of plasmacytoid carcinoma was described in the urothelium by Sahin et al (40). This tumor was characterized by lytic tumors involving the ribs and skull, which is confused as multiple myeloma. Plasmacytoid pathology was initially thought to be diagnostic of B-cell lymphoma and plasmacytoma, which is why many misdiagnoses have been made. However, plasmacytoid appearance can also is found in cells of non-B cell hematopoietic neoplasm and various non-hematopoietic derivatives. In 2006, two non-invasive bladder tumors, resembling plasmacytoma, were reported by Coyne and Sim (41). Subsequently, several other plasmacytoid urothelial carcinomas were described $(5-7,10-13,42,43)$, as well as cases of the ureter and renal pelvis $(15,16)$. Here, we describe a new case of plasmacytoid adenocarcinoma of the prostate, diagnosed on tumor core biopsy, presenting histological and molecular characteristics consistent with those recently described by Al- Hussain et al (8) and Nguyen et al (9), as shown Table I. We also emphasize the importance of obtaining immunohistochemical data as we explore the differential diagnosis of prostate cancer and distinguish it from other carcinomas with plasmacytoid features such as those of the genitourinary system.

In our presenting case, we analyzed several core biopsies of a prostate tumor and identified high-grade cancer with a Gleason score of $5+5$ (total score 10), in which tumor cells showed a plasmacytoid appearance, specifically, abundant cytoplasm and eccentrically placed hyperchromatic nuclei (Fig. 1). Our immunohistochemical data, which document tumor cells with strong immunoreactivity for cytokeratins AE1/AE3 and PSA, but negative for urothelial markers, such as p63, cytokeratin 34BE12, and GATA3, synaptophysin which is a neuroendocrine marker, and cell-cell adhesion molecule E-cadherin (Fig. 2C), which is particularly indicative of CDH1 alterations, are consistent with data from two previous reports of prostate plasmacytoid tumors $(8,9)$. Specifically, Al-Hussain et al (8) showed prostate tumor cells with a plasmacytoid appearance that were positive for cytokeratin 

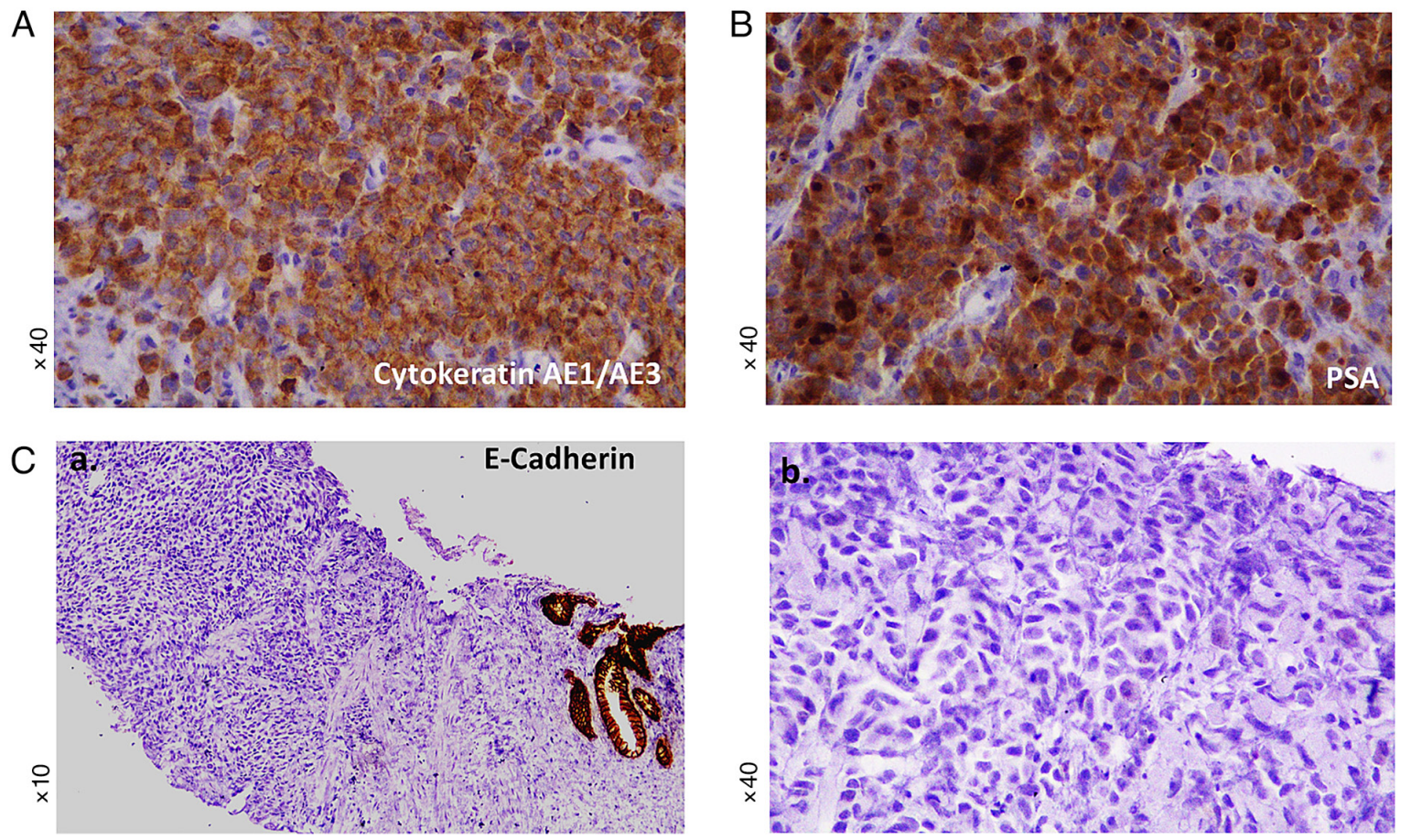

Figure 2. Immunohistochemical phenotype of plasmacytoid adenocarcinoma of the prostate. (A) Tumor cells were positive for cytokeratin AE1/AE3, as shown by immunohistochemical analysis (original magnification, $\mathrm{x} 40$ ). (B) Tumor cells were positive for PSA, as determined by immunohistochemical analysis (original magnification, $\mathrm{x} 40$ ). (C) Loss of E-cadherin in plasmacytoid prostatic adenocarcinoma. Compared with the (C-a) entrapped normal prostatic glands that show membranous positivity (original magnification, $\mathrm{x} 10$ ), (C-b) the tumor cells were negative for E-cadherin, as shown by immunohistochemical analysis (original magnification, $\mathrm{x} 40$ ). PSA, prostate specific antigen.

8/18, but negative for E-cadherin (Table I). Nguyen et al (9) also described a single-cell, high-grade adenocarcinoma of the prostate with a distinct subtype of plasmacytoid features with loss of E-cadherin and positive expression of cytoplasmic p120 catenin. It is worth mentioning that these previously described plasmacytoid features were analyzed from radical prostatectomy or local metastases, while here we present for the first time a case of plasmacytoid carcinoma described by prostate biopsy cores. This observation may emphasize the importance of differential diagnosis in prostate biopsy.

E-cadherin is one of the key molecules which form adhesive intercellular connections between epithelial cells $(44,45)$ and may play a key role in metastasis of prostate cancer. Loss of E-cadherin expression is a hallmark of the epithelial-to-mesenchymal transition (EMT) process, while epithelial cells that lose their ability to adhere to adjacent cells and extracellular matrix proteins acquire a mesenchymal phenotype (46). It is considered that a decrease in E-cadherin expression may occur during the development of prostate carcinoma, leading to migration, invasion, and eventual metastasis (47). However, the results of the studies are controversial, and the loss or aberrant expression of E-cadherin has been associated with a poor prognosis of prostate carcinoma through different mechanisms (47). In particular, the loss of E-cadherin and the abnormal expression of p120 catenin protein, through immunohistochemical analysis, strongly suggest changes in $\mathrm{CDH}$. Plasmacytoid urothelial carcinoma, lobular breast carcinoma, and diffuse gastric carcinoma have previously been shown to cause $\mathrm{CDHI}$ alterations leading to loss of function, along with loss of expression of E-cadherin, which is in the cell membrane (36). However, it has been previously suggested that other molecular pathways may also play a role in the prostate plasmacytoid variant, including alterations in FANCA, MET, SMARCA4, in addition to frameshift deletions in $B R A F$ and $K D R$, and a large loss of copy number at the $R B 1$ locus (8). Nevertheless, all these tumors typically present morphological characteristics of tumor cells that develop into a discohesive single-cell pattern due to the loss of cell-cell adhesions. In particular, the single-cell pattern of tumor infiltration in prostatic adenocarcinoma is clinically important as it meets the definition of the highest grade of Gleason-based architecture (48). Our data showed E-cadherin deficiency, using immunohistochemical analysis (8), in plasmacytoid adenocarcinoma of the prostate with a Gleason score of $5+5$ (total score 10), which supports a high-grade tumor with a single-cell pattern.

Taking all the above, the morphology of plasmacytoid tumors in the genitourinary system is not exclusive to urothelial carcinoma. Therefore, a differential diagnosis between high-grade adenocarcinoma of the prostate compared to high-grade urothelial carcinoma is needed to access the prognosis and provide the right treatment. As in our case, this can be aided by using a targeted panel of antibodies in immunohistochemistry, such as PSA (Fig. 2B), prostatic acid phosphatase (PAP), and NKX3.1 or protein antibodies to prostatic adenocarcinoma, as well as GATA3, p63, and 34BE12 antibodies to urothelial carcinoma (49). Specifically, PSA and GATA3 are recommended as first-line markers (49). In addition, high-grade prostatic adenocarcinoma can be distinguished from urinary bladder adenocarcinoma using the prostatic markers PSA, PAP, and prostein (49). Immunohistochemical analysis for villin, thrombomodulin, CDX2, and carcinoembryonic antigen (CEA) can be also used to indicate urinary 
Table I. Cases of prostatic adenocarcinoma with plasmacytoid features and the immunohistochemical and molecular phenotypes.

A, Previous cases

\begin{tabular}{|c|c|c|c|c|c|}
\hline \multirow[b]{2}{*}{ First author, year } & \multirow{2}{*}{$\begin{array}{l}\text { Number } \\
\text { of cases }\end{array}$} & \multicolumn{2}{|c|}{ Immunohistochemical staining } & \multirow[b]{2}{*}{ Molecular findings } & \multirow[b]{2}{*}{ (Refs.) } \\
\hline & & Positive & Negative & & \\
\hline $\begin{array}{l}\text { Al-Hussain et al, } \\
2019\end{array}$ & 1 & $\begin{array}{l}\text { NKX } 3.1, \text { PSA, } \\
\text { CK } 8 / 18 \text { and } \\
\text { PSAP }\end{array}$ & $\begin{array}{l}\text { 34BE12, CK20, p63, } \\
\text { Desmin, CD } 38, \kappa \text { and } \lambda \\
\text { light chains, chromogranin, } \\
\text { synaptophysin, GATA3, } \\
\text { E-cadherin and CD45 }\end{array}$ & $\begin{array}{l}\text { Next generation Sequencing } \\
\text { (HiSeq } 2500 \text { platform; Illumina, } \\
\text { Inc.) } \\
\text { Missense mutations in } F A N C A \\
\text { (p. L1339F), MET (p. R547G) } \\
\text { and SMARCA4 (p.Y820N) } \\
\text { Frameshift deletions in BRAF } \\
\text { and } K D R \\
\text { Large copy number loss of } \\
R B 1 \text { locus } \\
\text { No genomic alterations in } C D H 1\end{array}$ & (8) \\
\hline $\begin{array}{l}\text { Nguyen et al, } \\
2020\end{array}$ & 9 & $\begin{array}{l}\text { NKX3.1, PSA, } \\
\text { p120 and catenin }\end{array}$ & E-cadherin & Somatic alterations in $\mathrm{CDH} 1$ & (9) \\
\hline
\end{tabular}

B, Current study

\begin{tabular}{lcccc}
\hline & & \multicolumn{2}{c}{ Immunohistochemical staining } & \\
\cline { 3 - 4 } First author, year $\begin{array}{c}\text { Number } \\
\text { of cases }\end{array}$ & Positive & Negative & Molecular findings & N/A \\
\hline N/A & 1 & $\begin{array}{l}\text { CKAE1/AE3 } \\
\text { and PSA }\end{array}$ & $\begin{array}{l}\text { 34BE12, p63, } \\
\text { synaptophysin, GATA3 } \\
\text { and E-cadherin }\end{array}$ & N/A \\
\hline
\end{tabular}

NKX3.1, homeobox protein Nkx-3.1; PSA, prostate specific antigen; CK, cytokeratin; PSAP, prosaposin; GATA3, GATA binding protein 3; FANCA, Fanconi anemia group A protein; MET, hepatocyte growth factor receptor; SMARCA4, transcription activator BRG1; KDR, vascular endothelial growth factor receptor 2; RB1, retinoblastoma-associated protein; N/A, not applicable.

Table II. Cases of prostatic adenocarcinoma with plasmacytoid features and the histological and laboratory findings.

A, Previous cases

\begin{tabular}{|c|c|c|c|c|c|c|}
\hline \multirow[b]{2}{*}{ First author, year } & \multirow[b]{2}{*}{$\begin{array}{c}\text { Survived/total } \\
\text { cases }^{\text {a }}\end{array}$} & \multicolumn{2}{|c|}{ Tumor characteristics } & \multicolumn{2}{|c|}{ PSA } & \multirow[b]{2}{*}{ (Refs.) } \\
\hline & & $\begin{array}{c}\text { TNM } \\
\text { staging }\end{array}$ & $\begin{array}{l}\text { Gleason } \\
\text { score }\end{array}$ & $\begin{array}{l}\text { Before } \\
\text { treatment }\end{array}$ & $\begin{array}{c}\text { After } \\
\text { treatment }\end{array}$ & \\
\hline Al-Hussain et al, 2019 & $0 / 1$ & T4N1M1b & $10(5+5)$ & $50.7 \mathrm{ng} / \mathrm{ml}$ & $11.2 \mathrm{ng} / \mathrm{ml}$ & (8) \\
\hline Nguyen et al, 2020 & $4 / 9$ & $\begin{array}{l}\text { T2N0M0- } \\
\text { T3bN1M1b }\end{array}$ & $\begin{array}{c}8(3+5) \text { to } \\
9(5+4)\end{array}$ & N/A & Undetectable & (9) \\
\hline
\end{tabular}

B, Current case

\begin{tabular}{|c|c|c|c|c|c|c|}
\hline \multirow[b]{2}{*}{ First author, year } & \multirow[b]{2}{*}{$\begin{array}{c}\text { Survived/total } \\
\text { cases }^{\mathrm{a}}\end{array}$} & \multicolumn{2}{|c|}{ Tumor characteristics } & \multicolumn{2}{|c|}{ PSA } & \multirow[b]{2}{*}{ (Refs.) } \\
\hline & & $\begin{array}{c}\text { TNM } \\
\text { staging }\end{array}$ & $\begin{array}{l}\text { Gleason } \\
\text { score }\end{array}$ & $\begin{array}{c}\text { Before } \\
\text { treatment }\end{array}$ & $\begin{array}{c}\text { After } \\
\text { treatment }\end{array}$ & \\
\hline $\mathrm{N} / \mathrm{A}$ & $1 / 1$ & T3bNXM0 & $10(5+5)$ & $43.6 \mathrm{ng} / \mathrm{ml}$ & $\mathrm{N} / \mathrm{A}$ & $\mathrm{N} / \mathrm{A}$ \\
\hline
\end{tabular}

${ }^{a}<3$ years follow up. TNM, tumor node metastasis; PSA, prostate specific antigen; N/A, not applicable. 
bladder adenocarcinoma (49). In the case presented here, we obtained immunohistochemical data that confirmed the diagnosis of prostate carcinoma, distinguishing it from other carcinomas of the genitourinary system.

Overall, clinical features, immunohistochemical data including E-cadherin immunoreactivity, and the molecular profile in the prognosis of therapy selection of prostate tumors still need further validation (50). Al-Hussein et al (8) showed a case of plasmacytoid prostate metastatic tumor negative for E-Cadherin, but without $C D H 1$ genomic alterations (Table I). This tumor initially responded to antiandrogen therapy, which is considered the first-line treatment for prostate cancer with clinically detected metastases (51). However, the patient of that case died 6 months after diagnosis (Table II). In contrast, in our case, a plasmacytoid prostate tumor that was not metastatic at the time of diagnosis was negative for E-Cadherin, although it was not analyzed for $C D H 1$ mutations (Table I). This tumor was treated by radical prostatectomy, which is considered a treatment option for men with a localized prostate tumor. In addition, the patient is now alive, six months after diagnosis (Table II). Based on the above, assessing the association between E-cadherin loss along with $\mathrm{CDH} 1$ or other genomic alterations in plasmacytoid prostate tumor development and/or disease prognosis after treatment, like hormonal therapy, may be worth further investigation through preclinical models and therapy treatment studies.

In conclusion, the recognition of the newly described plasmacytoid variant of prostatic adenocarcinoma can be made in tissue biopsies. Identification of the irregular immunophenotype of this tumor may support the role of somatic changes in $\mathrm{CDH} 1$ in the development of the plasmacytoid pattern with loss of E-cadherin. Although some limitations may be mentioned, such as the evaluation of a non-extensive panel of immunohistochemical or molecular markers, including the lack of $C D H 1$ genomic analysis, due to small biopsy material, and access to clinical information, we believe that the presentation of a new rare prostatic carcinoma variant may contribute to better understanding this uncommon histological pattern that may be mandatory due to the clinical and prognostic implications of this diagnosis.

\section{Acknowledgements}

Not applicable.

\section{Funding}

No funding was received.

\section{Availability of data and materials}

The datasets used and/or analyzed during the current study are available from the corresponding author on reasonable request.

\section{Authors' contributions}

$\mathrm{KZ}$, DPV, GKK and MI were involved in conceiving and designing the study. KZ, GKK and MI contributed to patient data collection. MI, KZ and DPV confirm the authenticity of all the raw data. KZ, DPV, GKK and MI contributed to the interpretation of data. KZ, DV and MI were involved in the preparation of the original draft. DPV, MI, GKK and KZ critically revised the manuscript. All authors have read and approved the final manuscript.

\section{Ethics approval and consent to participate}

The patient was admitted to the General University Hospital of Larissa (Larissa Thessaly, Greece), which is a teaching hospital, and the patient signed a written consent for participation and publication of their associated data.

\section{Patient consent for publication}

Not applicable.

\section{Competing interests}

The authors declare that they have no competing interests.

\section{References}

1. Sung H, Ferlay J, Siegel RL, Laversanne M, Soerjomataram I, Jemal A and Bray F: Global cancer statistics 2020: GLOBOCAN estimates of incidence and mortality worldwide for 36 cancers in 185 countries. CA Cancer J Clin 71: 209-249, 2021.

2. Baade PD, Youlden DR and Krnjacki LJ: International epidemiology of prostate cancer: Geographical distribution and secular trends. Mol Nutr Food Res 53: 171-184, 2009.

3. Humphrey PA: Histopathology of prostate cancer. Cold Spring Harb Perspect Med 7: a030411, 2017.

4. Kweldam CF, van Leenders GJ and van der Kwast T: Grading of prostate cancer: A work in progress. Histopathology 74: 146-160, 2019.

5. Lopez-Beltran A, Requena MJ, Montironi R, Blanca A and Cheng L: Plasmacytoid urothelial carcinoma of the bladder. Hum Pathol 40: 1023-1028, 2009.

6. Fox MD, Xiao L, Zhang M, Kamat AM, Siefker-Radtke A, Zhang L, Dinney CP, Czerniak B and Guo CC: Plasmacytoid urothelial carcinoma of the urinary bladder: A clinicopathologic and immunohistochemical analysis of 49 cases. Am J Clin Pathol 147: 500-506, 2017.

7. Cockerill PA, Cheville JC, Boorjian SA, Blackburne A, Thapa P, Tarrell RF and Frank I: Outcomes following radical cystectomy for plasmacytoid urothelial carcinoma: Defining the need for improved local cancer control. Urology 102: 143-147, 2017.

8. Al-Hussain T, Haffner MC, Altaweel WM and Epstein JI: Plasmacytoid acinar adenocarcinoma of the prostate: A newly described variant of prostate cancer. Hum Pathol 94: 86-91, 2019.

9. Nguyen JK, Chen YY, Magi-Galluzzi C and McKenney JK: Clinicopathological study of Gleason pattern 5 prostatic adenocarcinoma with 'single-cell' growth reveal 2 distinct types, one with 'plasmacytoid 'features. Am J Pathol 44: 1635-1642, 2020.

10. Li Q, Assel M, Benfante NE, Pietzak EJ, Herr HW, Donat M, Cha EK, Donahue TF, Bochner BH and Dalbagni G: The impact of plasmacytoid variant histology on the survival of patients with urothelial carcinoma of bladder after radical cystectomy. Eur Urol Focus 5: 104-108, 2019.

11. Dayyani F, Czerniak BA, Sircar K, Munsell MF, Millikan RE, Dinney CP and Siefker-Radtke AO: Plasmacytoid urothelial carcinoma, a chemosensitive cancer with poor prognosis, and peritoneal carcinomatosis. J Urol 189: 1656-1661, 2013.

12. Ericson KJ, Thomas L and Lee BH: Plasmacytoid variant urothelial carcinoma: Clinicopathologic outcomes and experience with neoadjuvant chemotherapy. J Clin Oncol 37: 483, 2019.

13. Diamantopoulos LN, Khaki AR, Vakar-Lopez F, Tretiakova MS, Gore JL, Schade GR, Psutka SP, Hsieh AC, Lee JK, Hsieh AC, et al: Patient (pt) characteristics, treatment patterns, outcomes and prognostic factors in plasmacytoid urothelial carcinoma (PUC). J Clin Oncol 37 (Suppl 15): e16007-e16007, 2019.

14. Straccia P, Martini M, Sacco E, Bassi PF and Pierconti F: Cytological features of micropapillary and plasmacytoid variants of urothelial carcinoma. Diagn Cytopathol 48: 111-117, 2020. 
15. Jibril A and Steven AC: Plasmacytoid urothelial carcinoma of ureter with retroperitoneal metastasis: A case report. Am J Case Rep 19: 158-162, 2018.

16. Takada-Owada A, Nozawa Y, Onozaki M, Noda S, Jamiyan T, Tokura Y, Nakazato Y, Kamai T and Ishida K: Plasmacytoid urothelial carcinoma of renal pelvis with positive zinc finger E-box-binding homeobox 1: A case report. Diagn Pathol 15: 124, 2020.

17. Keck B, Wach S, Kunath F, Bertz S, Taubert H, Lehmann J, Stöckle M, Wullich B and Hartmann A: Nuclear E-cadherin expression is associated with the loss of membranous E-cadherin, plasmacytoid differentiation and reduced overall survival in urothelial carcinoma of the bladder. Ann Surg Oncol 20: 2440-2445, 2013.

18. Lim MG, Adsay NV, Grignon DJ and Osunkoya AO: E-cadherin expression in plasmacytoid, signet ring cell and micropapillary variants of urothelial carcinoma: Comparison with usual-type high-grade urothelial carcinoma. Mod Pathol 24: 241-247, 2011.

19. Ma B, Khazali A, Shao H, Jiang Y and Wells A: Expression of E-cadherin and specific CXCR 3 isoforms impact each other in prostate cancer. Cell Commun Signal 17: 164, 2019.

20. Sangoi AR, Chan E, Stohr BA and Kunju LP: Invasive plasmacytoid urothelial carcinoma: A comparative study of E-cadherin and P120 catenin. Hum Pathol 102: 54-59, 2020.

21. Palsgrove DN, Taheri D, Springer SU, Cowan M, Guner G, Rodriguez MA, Pena MDC, Wang Y, Kinde I, Ricardo BFP, et al: Targeted sequencing of plasmacytoid urothelial carcinoma reveals frequent TERT promoter mutations. Hum Pathol 85: 1-9, 2019.

22. Mohler JL, Antonarakis ES, Armstrong AJ, D'Amico AV, Davis BJ, Dorff T, Eastham JA, Enke CA, Farrington TA, Higano CS, et al: Prostate cancer version 2.2019, NCCN clinical practise guidelines in oncology. J Natl Compr Canc Netw 17: 479-505, 2019.

23. Nelson RS and Epstein JI: 1996. Prostatic carcinoma with abundant xanthomatous cytoplasm. Foamy gland carcinoma. Am J Surg Pathol 20: 419-426, 1996.

24. Cina SJ and Epstein JI: Adenocarcinoma of the prostate with atrophic feature. Am J Surg Pathol 21: 289-295, 1997.

25. Humphrey PA, Kaleem Z, Swanson PE and Vollmer RT: Pseudohyperplastic prostatic adenocarcinoma. Am J Surg Pathol 22: 1239-1246, 1998.

26. Wolf AN and Epstein JI: Pseudohyperplastic prostatic adenocarcinoma in needle biopsy and simple prostatectomy. Am J Surg Pathol 24: 1039-1046, 2000.

27. Yaskiv O, Cao D and Humphrey PA: Microcystic adenocarcinoma of the prostate: A variant of pseudohyperplastic and atrophic patterns. Am J Surg Pathol 34: 556-561, 2010.

28. Levi AW and Epstein JI: Pseudohyperplastic prostatic adenocarcinoma in needle biopsy and simple prostatectomy. Am J Surg Pathol 24: 1039-1046, 2000.

29. Lopez-Beltran A, Eble JN and Bostwick DG: Pleomorphic giant cell carcinoma of the prostate. Arch Pathol Lab Med 129: 683-685, 2005

30. Parwani AV, Herawi M and Epstein JI: Pleomorphic giant cell adenocarcinoma of the prostate: Report of 6 cases. Am J Surg Pathol 30: 1254-1259, 2006.

31. Hansel DE and Epstein JI: Sarcomatoid carcinoma of the prostate: A study of 42 cases. Am J Surg Pathol 30: 1316-1321, 2006.

32. Epstein JI, Amin MB, Reuter VE and Humphrey PA: Contemporary gleason grading of prostatic carcinoma: An update with discussion of practical issues to implement the 2014 international society of urological pathology (ISUP) consensus conference on gleason grading of prostatic carcinoma. Am J Surg Pathol 41: e1-e7, 2017

33. Humphrey PA: Variants of acinar adenocarcinoma of the prostate mimicking benign conditions. Mod Pathol 31 (S1): S64-S70, 2018.

34. Gottipati S, Warncke J, Vollmer R and Humphrey PA: Usual and unusual histologic patterns of high Gleason score 8 to 10 adenocarcinoma of the prostate in needle biopsy tissue. Am J Surg Pathol 36: 900-907, 2012.
35. Epstein JI, Egevad L, Amin MB, Delahunt B, Srigley JR and Humphrey PA; Grading Committee: The 2014 international society of urological pathology (ISUP) consensus conference on gleason grading of prostatic carcinoma: Definition of grading patterns and proposal for a new grading system. Am J Surg Pathol 40: 244-252, 2016.

36. Al-Ahmadie HA, Iyer G, Lee BH, Scott SN, Mehra R, Bagrodia A, Jordan EJ, Gao SP, Ramirez R, Cha EK, et al: Frequent somatic CDH1 loss-of-function mutations in plasmacytoid variant bladder cancer. Nat Genet 48: 356-358, 2016.

37. Schrader KA, Masciari S, Boyd N, Wiyrick S, Kaurah P, Senz J, Burke W, Lynch HT, Garber JE and Huntsman DG: Hereditary diffuse gastric cancer: Association with lobular breast cancer. Fam Cancer 7: 73-82, 2008

38. Oliveira C, Senz J, Kaurah P, Pinheiro H, Sanges R, Haegert A, Corso G, Schouten J, Fitzgerald R, Vogelsang H, et al: Germline $\mathrm{CDH} 1$ deletions in hereditary diffuse gastric cancer families. Hum Mol Genet 18: 1545-1555, 2009.

39. Keller G, Vogelsang H, Becker I, Hutter J, Ott K, Candidus S, Grundei T, Becker KF, Mueller J, Siewert JR and Höfler H: Diffuse type gastric and lobular breast carcinoma in a familial gastric cancer patient with an E-cadherin germline mutation. Am J Pathol 155: 337-342, 1999.

40. Sahin AA, Myhre M, Ro JY, Sneige N, Dekmezian RH and Ayala AG: Plasmacytoid transitional cell carcinoma. Report of a case with initial presentation mimicking multiple myeloma. Acta Cytol 35: 277-280, 1991.

41. Coyne JD and Sim E: Urothelial neoplasia with plasmacytoid morphology. Histopathology 48: 200-201, 2006.

42. Wang YG, Perera M and Gleeson J: Plasmacytoid urothelial carcinoma of the bladder with extensive scrotal wall invasion. Urol Ann 8: 381-383, 2016.

43. Fritsche HM, Burger M, Denzinger S, Legal W, Goebell PJ and Hartmann A: Plasmacytoid urothelial carcinoma of the bladder: Histological and clinical features of 5 cases. J Urol 180: 1923-1927, 2008.

44. Bougen NM, Amiry N, Yuan Y, Kong XJ, Pandey V, Vidal LJ, Perry JK, Zhu T and Lobie PE: Trefoil factor 1 suppression of E-CADHERIN enhances prostate carcinoma cell invasiveness and metastasis. Cancer Lett 332: 19-29, 2013.

45. Nauseef JT and Henry MD: Epithelial-to-mesenchymal transition in prostate cancer: Paradigm or puzzle? Nat Rev Urol 8: 428-439, 2011

46. Lee HM, Hwang KA and Choi KC: Diverse pathways of epithelial mesenchymal transition related with cancer progression and metastasis and potential effects of endocrine disrupting chemicals on epithelial mesenchymal transition process. Mol Cell Endocrinol 457: 103-113, 2017.

47. Chunthapong J, Seftor EA, Khalkhali-Ellis Z, Seftor RE, Amir S, Lubaroff DM, Heidger PM Jr and Hendrix MJ: Dual roles of E-cadherin in prostate cancer invasion. J Cell Biochem 91: 649-661, 2004

48. Epstein JI: Prostate cancer grading: A contemporary photomontage. Am J Surg Pathol 40: 137, 2016.

49. Epstein JI, Egevad L, Humphrey PA and Montironi R; Members of the ISUP Immunohistochemistry In Diagnostic Urologic Pathology Group: Best practices recommendations in the application of immunohistochemistry in the prostate: Report from the international society of urologic pathology consensus conference. Am J Surg Pathol 38: e6-e19, 2014

50. Dehm SM and Tindall DJ: Molecular regulation of androgen action in prostate cancer. J Cell Biochem 99: 333-344, 2006.

51. Zhang X, Zhang Z, Chen S, Jiang J, Qi R, Mi X, Zhang X, Xi Y, Zheng $\mathrm{H}$ and Hua B: Prognostic significance of E-cadherin expression in prostatic carcinoma: A protocol for systematic review and meta-analysis. Medicine (Baltimore) 99: e19707, 2020. 